\title{
Agency-Communion and Self-Esteem Relations are Moderated by Culture, Religiosity, Age, and Sex: Evidence for the "Self-Centrality Breeds Self-Enhancement" Principle
}

\begin{tabular}{|r|l|}
\hline Journal: & Journal of Personality \\
\hline Manuscript ID: & JOPY-12-0107.R2 \\
\hline Manuscript Type: & Original Manuscript \\
\hline Date Submitted by the Author: & n/a \\
\hline Keywords: & $\begin{array}{l}\text { Gebauer, Jochen; Humboldt-Universität zu Berlin, Institut für Psychologie } \\
\text { Wagner, Jenny; Humboldt-Universität zu Berlin, Institut für Psychologie } \\
\text { Nedikides, Constantine }\end{array}$ \\
\hline &
\end{tabular}

SCHOLARONE $^{m}$
Manuscripts 


\section{Running Head: AGENCY-COMMUNION AND SELF-ESTEEM}

Agency-Communion and Self-Esteem Relations Are Moderated by

Culture, Religiosity, Age, and Sex:

Evidence for the "Self-Centrality Breeds Self-Enhancement" Principle

Jochen E. Gebauer Jenny Wagner

Humboldt-Universität zu Berlin

Constantine Sedikides

University of Southampton

Wiebke Neberich

Affinitas $\mathrm{GmbH}$

We thank Andreas Nehrlich for helpful comments on an earlier draft of this manuscript.

Please address correspondence to Jochen Gebauer, Humboldt-Universität zu Berlin, Institut für Psychologie, Unter den Linden 6, 10099 Berlin, Deutschland; email:

mail@JochenGebauer.info. 


\begin{abstract}
Objective: Who has high self-esteem? Is it ambitious, competitive, outgoing people —agentic personalities? Or is it caring, honest, understanding people — communal personalities? The literature on agency-communion and self-esteem is sparse, indirect, and inconsistent. Based on William James's theorizing, we propose the self-centrality breeds self-enhancement principle. Accordingly, agency will be linked to self-esteem, if agency is self-central. Conversely, communion will be linked to self-esteem, if communion is self-central. But what determines the self-centrality of agency and communion? The literature suggests that agency is self-central in agentic cultures, as well as among non-religious individuals, men, and younger adults. Communion is self-central in communal cultures, as well as among religious individuals, women, and older adults. Method: 187,957 people $(47 \%$ female; mean age $=$ 37.49 years, $S D=12.22$ ) from 11 cultures were examined. The large sample size afforded us to test simultaneously the effect of all four moderators in a single two-level model (participants nested in cultures). Results: Results supported the unique moderating effect of culture, religiosity, age, and sex on the relation between agency-communion and self-esteem. Conclusions: Agentic and communal people can both have high self-esteem, depending on self-centrality of agency and communion.
\end{abstract}

KEYWORDS: self-esteem, agency, communion, self-centrality, culture. 
Humans want to feel worthy (Alicke \& Sedikides, 2011). They describe self-esteem as a key ingredient of their most satisfying life-events (Sheldon, Elliot, Kim, \& Kasser, 2001). They choose self-esteem boosts over eating favorite foods, receiving paychecks, seeing best friends, and engaging in favorite sexual activities (Bushman, Moeller, \& Crocker, 2011). And they rely on self-esteem to cope with existential fear and sustain their health and motivation (Routledge et al., 2010).

If high self-esteem is so important, are there certain personality factors that are more strongly linked to self-esteem than others? This question is central to personality psychology, because it provides one answer to what the subjectively desirable personality is. Further, because self-esteem is a major predictor of health, a better insight about personality underpinnings of self-esteem is objectively desirable (e.g., for health care providers and clinicians). In this article, we examined self-esteem's relation to the "Big Two" personality dimensions of agency (e.g., ambitious, competitive, outgoing) and communion (e.g., caring, honest, understanding). We found the relevant literature to be sparse, indirect, and inconsistent. Some of the archival research suggests that self-esteem is more strongly linked to agency than to communion, other research indicates the opposite, and yet other research advocates that self-esteem is equally (and strongly) linked to agency and to communion.

Apart from these inconsistencies, the literature has assumed static relations between agency-communion and self-esteem (Leary, 1957; Sullivan, 1953; Wojciszke, Baryla, Parzuchowski, Szymkow, \& Abele, 2011). We adopt a more flexible approach. Our perspective dates back to William James (1907), who was the first psychologist to propose that meeting standards of high self-centrality constitutes the main source of self-esteem-a principle we label self-centrality breeds self-enhancement. We expect, then, a relatively strong relation between agency and self-esteem, if agency is self-central. In other words, if agentic self-attributes are personally important to an individual, this individual should derive much self-esteem from possessing agentic self-attributes. Conversely, we expect a relatively strong relation between communion and self-esteem, if communion is self-central. In other words, if communal self-attributes are personally important to an individual, this individual should derive much self-esteem from possessing communal self-attributes. 
What factors render agency and communion self-central? We examine the following four, taking the lead from extant literature: culture-level agency and communion, personal religiosity, sex, and age. We test our perspective (i.e., self-centrality breeds self-enhancement) in a large $(N=187,957)$, cross-cultural (11 countries), and sex-balanced ( $47 \%$ women) sample, that spans across a wide age-range (18-99 years) and is diverse in religiosity. Arguably, the strongest feature of our sample is that its size allows testing for the unique moderating effects of culture, religiosity, sex, and age on the agency-communion and selfesteem relation. Support for our perspective may help reconcile empirical inconsistencies.

\section{The Importance of Understanding Sources of Self-Esteem}

Lay people perceive self-esteem as subjectively important (Sheldon et al., 2001). Psychologists do the same (Sedikides \& Gregg, 2003). In fact, self-esteem is the most widely studied trait in psychology (Judge, Erez, Bono, \& Thoresen, 2002). Such immense interest is likely sparked by self-esteem's consequences. For example, low self-esteem is a major predictor of psychological ill-being (Sedikides, Rudich, Gregg, Kumashiro, \& Rusbult, 2004), perceived relationship problems (Murray, Holmes, \& Griffin, 2000), and substance abuse (DuBois \& Flay, 2004). Thus, it is crucial to understand self-esteem's sources. Agencycommunion suggests itself as a promising source, because, compared to self-esteem, agencycommunion is more basic (Abele \& Bruckmüller, 2011), genetically influenced (Neiss et al., 2005), and situationally stable (Leary \& Baumeister, 2000).

\section{Agency and Communion}

Personality traits can be organized in higher-order factors. Several factorial solutions have been proposed, ranging from a single factor (Musek, 2007) up to seven factors (Benet \& Waller, 1995). All these solutions have their strengths and weaknesses. We subscribe to organizing personality into the two-factor solution of agency and communion (Bakan, 1966).

Agency-communion entail features that render them an appealing framework for studying personality. These Big Two are widely applicable and unifying. At the level of selfperception, they can subsume other higher order factor solutions, such as the popular Big Five (Paulhus \& John, 1998; Saucier, 2009), but they are also pertinent to organizing social values (Trapnell \& Paulhus, 2012), interpersonal behaviors (Wiggins, 1991), interpersonal problems 
(Horowitz et al., 1988), self-enhancement strategies (Paulhus \& John, 1998), and developmental goals (Charles \& Carstensen, 2010). Over and above level of self-perception, agency-communion can organize person-perception (Abele \& Wojciszke, 2007), sex differences (Eagly \& Wood, 1999), group-perception (Fiske, Cuddy, Glick, \& Xu, 2002), and cultural differences (Markus \& Kitayama, 1991). Additionally, agency-communion can be distinguished clearly even at early stages of information processing, such as recognition, categorization, and inference formation (Abele \& Bruckmüller, 2011).

Agency-communion also possess features that make them particularly suitable for studying personality and self-esteem across cultures, religiosity, sex, and age. As to culture, the Big Two emerge across cultures (Abele, Uchronski, Suitner, \& Wojciszke, 2008), which is not the case for all higher-order factor solutions (John \& Srivastava, 1999). As to religiosity, agentic and communal themes are deeply embedded in the scripture of most world religions (Bakan, 1966). As to sex, masculinity can be mapped onto agency, whereas femininity can be mapped onto communion (Bem, 1974; Wiggins, 1991), rendering agencycommunion highly relevant to the study of sex differences. Finally, as to age, agencycommunion can organize parsimoniously developmental challenges across the life span (i.e., performance-goals and social-goals; Charles \& Carstensen, 2010).

\section{Agency-Communion and Self-Esteem: Prior Perspectives}

Do agentic and/or communal individuals possess higher self-esteem? Some research suggests that agentic, but not communal, individuals have higher self-esteem. First, agency is tied to independent self-construals and communion is tied to interdependent self-construals (Wojciszke, 1997), and only independent self-construals appear to relate to higher self-esteem (Singelis et al., 1999; but see Cheng et al., 2011). Second, Abele et al. (2008) asked participants to classify the construct "self-confidence" along agency-communion dimensions. For lay people, self-confidence seems identical to self-esteem, and participants subjectively classified self-confidence into the high agency category, but not into the high communion category. Finally, Wojciszke et al. (2011) provided an explicit test of the relation between agency-communion and self-esteem, examining Polish high school students, college students, young employees, and older state clerks. Across all these samples, agency was strongly 
related to self-esteem, whereas communion was weakly related to self-esteem at best (with the exception of older state clerks, for whom communion was moderately related to self-esteem).

However, other research suggests that communal individuals, more so than agentic ones, have higher self-esteem. First, Schwartz and Bardi (2001) examined values across many participants and cultures. They found that people universally cherish a communal valueorientation more than they cherish an agentic value-orientation, and values are widely regarded as the "conceptual tools and weapons that we all employ in order to maintain and enhance self-esteem" (Rokeach, 1973; p. 14). Second, extraversion and openness are core elements of agency, whereas agreeableness and conscientiousness are core elements of communion (Paulhus \& John, 1998; Saucier, 2009), and neuroticism and self-esteem share a genetic core (Neiss, Stevenson, Legrand, Iacono, \& Sedikides, 2009) or "may be markers of the same higher order concept" (Judge et al., 2002). Therefore, it is informative to find out whether low neuroticism (proxy for self-esteem) is more strongly tied to extraversionopenness (proxy for agency) or to agreeableness-conscientiousness (proxy for communion). DeYoung (2006) addressed this issue via factor analyses. He obtained a two factor solution with one factor including extraversion-openness, and the other factor including agreeablenessconscientiousness and neuroticism. Self-esteem (i.e., neuroticism), then, is closer tied to communion than agency. Finally, the Muhammad Ali effect (Allison, Messick, \& Goethals, 1989) refers to the phenomenon whereby individuals inflate themselves more strongly on honesty (a communal trait) than on intelligence (an agentic trait). Van Lange and Sedikides (1998) examined the basis of the Muhammad Ali effect and localized it to the larger selfenhancement potential of honesty compared to intelligence.

Yet, other research suggests that agentic and communal individuals have similarly high levels of self-esteem. First, Crocker and Wolfe (2001) asked US college students to list their self-esteem contingencies. Among the seven contingencies listed, two relatively narrow ones (i.e., school competence and competition) were agentic, whereas a broader one (i.e., virtue) was communal (see also Coopersmith, 1967). Second, Robins, Tracy, Trzesniewski, Potter, and Gosling (2001) examined the relation between the Big Five and self-esteem in a sample of over 300,000 participants. Both extraversion-openness (i.e., agentic aspects) and 
agreeableness-conscientiousness (i.e., communal aspects; Saucier, 2009) were on average moderately related to self-esteem. Schmitt and Allik (2005) reported similar relations at the country-level. Third, Campbell, Rudich, and Sedikides (2002) investigated the relation between self-esteem and self-perceptions of agency-communion, relative to agencycommunion perceptions of the average peer (i.e., better-than-average perceptions). Across three samples, agentic and communal better-than-average perceptions were both related to higher self-esteem. In a similar vein, Gebauer, Sedikides, Verplanken, and Maio (in press) tested the relation between self-esteem and narcissism in the agentic as well as in the communal domain. Across two samples, agentic and communal narcissism were both independently related to higher self-esteem. Finally, Zeigler-Hill (2010) examined the relation between various measures of self-esteem and the interpersonal adjective scale (Wiggins, 1995). He found that global self-esteem (Rosenberg Self-Esteem Scale--Rosenberg, 1965;

State Self-Esteem Scale--Heatherton \& Polivy, 1991) was most strongly related to the Gregarious-Extraverted subscale of the interpersonal adjective scale, and this subscale marks individuals who are high on agency as well as high on communion (Wiggins, 1991).

In all, evidence regarding the relation between agency-communion and self-esteem is inconsistent. Part of the evidence suggests that agency is more strongly related to self-esteem than is communion. Another part, however, suggests that communion is more strongly related to self-esteem than is agency. A third part suggests that agency and communion are equivalently (and strongly) related to self-esteem. Next, we elaborate on the self-centrality breeds self-enhancement principle. We contend that applying this principle to the relation between agency-communion and self-esteem helps to resolve empirical contradictions.

\section{Self-Centrality Breeds Self-Enhancement}

"I, who for the time have staked my all on being a psychologist, am mortified if others know much more psychology than I. But I am contented to wallow in the grossest ignorance of Greek. My deficiencies there give me no sense of personal humiliation at all. Had I 'pretensions' to be a linguist, it would have been just the reverse." (James, 1907, p. 31) 
Meeting standards of high self-centrality (Verplanken \& Holland, 2001) constitutes the primary source of self-esteem. William James was the first psychologist with this insight, a principle to which we refer as self-centrality breeds self-enhancement. The principle has been frequently endorsed by researchers. For example, the self-evaluation maintenance model (Tesser, 2000) posits that being outperformed by others decreases self-esteem, but only when one is outperformed "in an area that is relevant to one's own self-definition" (Tesser \& Campbell, 1980, p. 341). Harter (1993) argued that children's and adolescents' self-esteem arises from meeting personal standards, but only when these standards are subjectively important to the individual. The self-enhancing tactician model proposes that "people are most likely to [self-]enhance on important self-attributes” (Sedikides \& Strube, 1997, p. 245).

Empirical evidence backs the self-centrality breeds self-enhancement principle. For example, individualistic qualities are more self-central to Westerners than to East-Asians, and the reverse is true for collectivist qualities. Hence, Westerners will inflate their individualist qualities (e.g., leadership, originality), whereas East-Asians will inflate their collectivist qualities (e.g., cooperativeness, loyalty). Evidence is consistent with these predictions (Gaertner, Sedikides, \& Chang, 2008; Sedikides, Gaertner, \& Toguchi, 2003; Sedikides, Gaertner, \& Vevea, 2005). Further, independent of culture, there is a positive relation between the (self-reported) self-centrality of agency-communion and the magnitude of selfenhancement bias on agency-communion (Brown, 2012; Gebauer, Lei, Cai, Gaertner, \& Sedikides, 2012b). This latter research measured self-enhancement in terms of unrealistically positive self-conceptions (e.g., better-than-average perceptions-Brown, 2012; overclaiming knowledge-Gebauer et al., 2012b), but it did not examine the relation between agencycommunion and self-esteem as a function of agency-communion's self-centrality. Thus, closing this gap, we hypothesize that agency will predict self-esteem particularly strongly among individuals for whom agency is self-central. Conversely, communion will predict selfesteem particularly strongly among individuals for whom communion is self-central.

What factors conduce to agency and communion being more or less self-central? We submit that there are many such factors, and thus our aim is not to supply a comprehensive list of them. Rather, we select four basic, broad, and relevant factors in order to illustrate the 
workings of the self-centrality breeds self-enhancement principle within the relation between agency-communion and self-esteem. These four factors are: culture-level agency and communion, personal religiosity, sex, and age.

Cultural norms constitute a pivotal source of self-centrality (Cai et al., 2011; Markus \& Kitayama, 1991; Sedikides \& Gregg, 2008). As such, agentic individuals will have relatively high self-esteem in cultures high on agency. Conversely, communal individuals will have relatively high self-esteem in cultures high on communion. These hypotheses are consistent with terror management theory (TMT; Greenberg, Solomon, \& Pyszczynski, 1997). For TMT, "self-esteem is ultimately a culturally based construction that consists of viewing oneself as living up to specific contingencies of value (cf. Crocker \& Wolfe, 2001) that are derived from the culture at large but are integrated into a unique individualized worldview by each person” (Pyszczynski, Greenberg, Solomon, Arndt, \& Schimel, 2004, p. 437).

A person's degree of religiosity will also impact the self-centrality of agency and communion. To begin with, religiosity is a good candidate to influence self-centrality, because religiosity exerts major effects on most religious people's daily life (Diener, Tay, \& Myers, 2011). At the same time, religious doctrine is outspoken about the importance of agency-communion. Specifically, teachings of all world religions encourage communion (Bakan, 1966; Sedikides \& Gebauer, 2010), but are less encouraging of agency and frequently discourage certain aspects of agency (e.g., competitiveness, dominance; Bakan, 1966; Sedikides \& Gebauer, 2010, in press). As such, the relation between agency and self-esteem will not be particularly strong among religious individuals. In fact, this relation may even be weaker than among non-religious individuals. In contrast, the relation between communion and self-esteem will be relatively strong among religious individuals.

A person's sex will additionally impact the self-centrality of agency and communion. For men, agency is relatively self-central, whereas for women communion is relatively selfcentral (Bem, 1974; Eagly \& Wood, 1999). As such, the relation between agency and selfesteem will be stronger among men, whereas the relation between communion and selfesteem will be stronger among women. Suggestive evidence supports this hypothesis. Wagner, Lüdtke, Jonkmann, and Trautwein (in press) studied the longitudinal effects of 
agreeableness (a core element of communion; Paulhus \& John, 1998) on self-esteem. Agreeableness did not predict self-esteem for men, but predicted self-esteem for women.

Finally, a person's age will also impact the self-centrality of agency and communion. Carstensen and colleagues (Charles \& Carstensen, 2011; Lang \& Carstensen, 2002) have documented that younger adults strive for performance related goals and thus perceive agency as relatively self-central, whereas older adults strive for socio-emotional goals and thus perceive communion as relatively self-central. Additionally, the hypothesized age-differences in the self-centrality of agency-communion correspond to findings regarding age-differences in the memory for agentic and communal content (Fung \& Carstensen, 2003) as well as agedifferences in social network structure (Wrzus, Köckeritz, Wagner, \& Neyer, in press). Together, the relation between agency and self-esteem will be stronger among younger adults, and the relation between communion and self-esteem will be stronger among older adults.

To summarize, we examine the moderating influence of culture, religiosity, sex, and age on the relation between agency-communion and self-esteem. These four moderators are not independent. For example, women are more religious than men, and older adults are more religious than younger adults (Batson, Schoenrade, \& Ventis, 1993). Therefore, it is critical to examine simultaneously the unique effects of the four moderators within a single mathematical model. The large size of the present sample afforded such a practice.

\section{Method}

\section{Participants}

We analyzed data from 187,957 individuals (47\% female; mean age $=37.49$ years, $S D$ $=12.22$ ) from the eDarling dataset (Gebauer, Sedikides, \& Neberich, 2012b). eDarling is a European online-dating site, which is active in 11 European countries. Participants provided self-reports of their country of residence. Based on these reports, the sample was distributed as follows: $9 \%$ Austria $(N=17,109), 10 \%$ France $(N=18,105), 10 \%$ Germany $(N=19,318)$, $7 \%$ Italy $(N=13,899), 10 \%$ Poland $(N=18,789), 10 \%$ Russia $(N=19,734), 9 \%$ Spain $(N=$ 17,339), 10\% Sweden $(N=19,457), 6 \%$ Switzerland $(N=11,183), 7 \%$ The Netherlands $(N=$ 13,552), and 10\% Turkey $(N=19,472)$.

\section{Materials}


Participants responded to many self-report items while completing their dating profile at the online-dating site eDarling. We relied on these items (with no influence over their content) to form composite measures of individual-level self-esteem, individual-level agency and communion, culture-level agency and communion, and individual-level religiosity.

Self-esteem. The 12-item eDarling Trait Self-Esteem Scale (Gebauer, Leary, \& Neberich, in press-a) is adapted from Heatherton and Polivy's (1991) State Self-Esteem Scale. Example items of our scale are: "I perceive myself as skilled in social situations," "I am proud of my educational background," and "I am satisfied with my physical appearance" $(1=$ not at all, $7=$ very much; $\alpha=.83$ ). The scale manifested metric equivalence, factor variance equivalence, and error variance equivalence across all 11 cultures of the present sample: unconstraint RMSEA = .020, fully constraint RMSEA = .024 (Bollen \& Curran, 2006; Cheung \& Rensvold, 2002). An independent validation study $(N=347)$ established that our scale measured a construct equivalent to that measured by the original Heatherton and Polivy scale. Specifically, we obtained a high correlation, $r=.77, p<.001$, between a latent global self-esteem variable defined by our scale's three subscales and a latent global self-esteem variable defined by the original scale's three subscales (see also Gebauer et al., in press-a).

These strong validity indices notwithstanding, the original scale, as well as our adaptation, assesses global self-esteem via aggregation of self-esteem facets. The aggregation approach is well-suited, considering the high correlation between Heatherton and Polivy's scale and scales that assess global self-feelings $(r=-.76$ with the Feelings of Inadequacy Scale_-Janis \& Field, 1959; $r=.71$ with the Rosenberg Self-Esteem Scale-Rosenberg, 1965). Nonetheless, to assure further that our measure assesses global self-esteem, we implemented the g-factor approach that is common in intelligence research (Jensen, 1998). Specifically, we subjected our subscales to an exploratory factor analysis. A single factor emerged, and this g-factor explained $63 \%$ of the total variance. As is customary in intelligence research (Jensen, 1998), we saved this factor (via the regression method) as our measure of global self-esteem. We repeated all analyses reported in this article with the more standard way of averaging the scores of the 12 items. Results were conceptually identical.

Agency-Communion. The 20-item eDarling Agency-Communion Scale (Gebauer, 
Paulhus, \& Neberich, in press-c) asks participants "How well does each of the following generally describe you?," tracked by 10 agentic items (i.e., adventuresome, ambitious, bossy, clever, competitive, dominant, leader, outgoing, rational, wise; $\alpha=.78$ ) and 10 communal items (i.e., affectionate, caring, compassionate, faithful, honest, kind, patient, sensitive, trusting, understanding; $\alpha=.86)(1=$ not at all to $7=$ very much $)$. The scale manifested metric equivalence, factor variance equivalence, and error variance equivalence across all 11 cultures of the current sample: unconstraint RMSEA $=.026$, fully constraint RMSEA $=.031$. Finally, the above described independent validation study showed that our Agency subscale loaded highly on a single factor together with well-established agency subscales (.87; crossloading: -.09) devised by Abele et al. (2008), Fiske et al. (2002), and Trapnell and Paulhus (2012). At the same time, our Communion subscale loaded highly on a single factor together with the corresponding well-established communion subscales (.91; cross-loading: .17).

Culture-level agency-communion. Previous research with the present eDarling sample showed that the mean of individual-level scores for each culture constitutes a suitable index of this construct at the culture-level (for culture-level mate-preferences, see Gebauer, Leary, \& Neberich, in press-b; for religiosity, see Gebauer et al., in press-c, 2012b). Thus, we obtained culture-level agency and communion indices by averaging the individual-level scores within each culture. ${ }^{1}$ Theoretically, averages of individual-level scores within a culture should reflect cultural norms (Schmitt, 2005; Oyserman et al., 2002), and empirical evidence has supported this theoretical claim (Gebauer et al., 2012; Sedikides \& Gebauer, 2010).

Religiosity. Participants completed the single-item "My personal religious beliefs are important to me" $(1=$ not at all, $7=$ very much $)$. Single-item religiosity measures are common and effective. Further, this measure was validated within the eDarling sample (Gebauer et al., in press-c, 2012b). Finally, the abovementioned independent validation study $(N=347)$ showed that this single-item measure loaded strongly on a general religiosity factor (.90) together with the Duke Religion Index (Koenig, Meador, \& Parkerson, 1997) and the Global Religiosity Measure (Gebauer \& Maio, 2012).

\section{Statistical Analyses}


A foremost strength of the current sample is that its size allows us to test simultaneously all four moderation effects within a single mathematical model (akin to a simultaneous multiple regression analysis). Participants were nested in cultures. Therefore, we tested our hypotheses within a two-level model, using the software HLM 6.06 (Raudenbush, Bryk, \& Congdon, 2004). Given that our hypotheses involved cross-level interactions, we followed recommendations to center all level 1 predictors around their group means (i.e., culture means; except of sex, which is dichotomous and thus should be dummy-coded; Raudenbush, 1989). We specified the following two-level model:

LEVEL 1 MODEL (italic: no centering, bold: group-mean centering) self-esteem $=\beta_{0}+\beta_{1}($ agency $)+\beta_{2}($ communion $)+\beta_{3}($ sex $)+\beta_{4}($ agency $\times$ sex $)+$ $\beta_{5}($ communion $\times$ sex $)+\beta_{6}($ religiosity $)+\beta_{7}($ agency $\times$ religiosity $)+\beta_{8}($ communion $\times$ religiosity $)+\beta_{9}($ age $)+\beta_{10}($ agency $\times$ age $)+\beta_{11}($ communion $\times$ age $)+r$

where a person's self-esteem is a combination of an individual-specific intercept, $\beta_{0}$, individual-specific linear slopes of agency, $\beta_{1}$, communion, $\beta_{2}$, sex, $\beta_{3}$, the interaction of agency and sex, $\beta_{4}$, the interaction of communion and sex, $\beta_{5}$, religiosity, $\beta_{6}$, the interaction of agency and religiosity, $\beta_{7}$, the interaction of communion and religiosity, $\beta_{8}$, age, $\beta_{9}$, the interaction of agency and age, $\beta_{10}$, the interaction of communion and age, $\beta_{11}$, and a residual error, r. Individual-specific intercepts and slopes were then modeled as level 2 outcomes

LEVEL 2 MODEL (bold italic: grand-mean centering)

$$
\begin{aligned}
& \beta_{0}=\gamma_{00}+\gamma_{01}(\text { agency })+\gamma_{02}(\text { communion })+\mathrm{u}_{0} \\
& \beta_{1}=\gamma_{10}+\gamma_{11}(\text { agency })+\gamma_{12}(\text { communion }) \\
& \beta_{2}=\gamma_{20}+\gamma_{21}(\text { agency })+\gamma_{22}(\text { communion }) \\
& \beta_{3}=\gamma_{30}+\gamma_{31}(\text { agency })+\gamma_{32}(\text { communion }) \\
& \beta_{4}=\gamma_{40}+\gamma_{41}(\text { agency })+\gamma_{42}(\text { communion }) \\
& \beta_{5}=\gamma_{50}+\gamma_{51}(\text { agency })+\gamma_{52}(\text { communion }) \\
& \beta_{6}=\gamma_{60}+\gamma_{61}(\text { agency })+\gamma_{62}(\text { communion })
\end{aligned}
$$




$$
\begin{aligned}
& \beta_{7}=\gamma_{70}+\gamma_{71}(\text { agency })+\gamma_{72}(\text { communion }) \\
& \beta_{8}=\gamma_{80}+\gamma_{81}(\text { agency })+\gamma_{82}(\text { communion }) \\
& \beta_{9}=\gamma_{90}+\gamma_{91}(\text { agency })+\gamma_{92}(\text { communion }) \\
& \beta_{10}=\gamma_{100}+\gamma_{101}(\text { agency })+\gamma_{102}(\text { communion }) \\
& \beta_{11}=\gamma_{110}+\gamma_{111}(\text { agency })+\gamma_{112}(\text { communion })
\end{aligned}
$$

where $\gamma_{00}$, to $\gamma_{110}$ are sample means, $\gamma_{01}$ (agency) to $\gamma_{111}$ (agency) are sample-specific slopes of culture-level agency, and $\gamma_{01}$ (communion) to $\gamma_{111}$ (communion) are sample-specific slopes of culture-level communion. Finally, $\mathrm{u}_{0}$ is the error term at level 2.

We additionally tested for the proportion of variance in self-esteem explained by each moderator. An appropriate test of this issue constitutes the comparison of two models for each moderator. Model A only includes the predictors (agency, communion) and the criterion (selfesteem). Model B additionally includes the moderator. The difference between the variances explained by Models A and B (at both levels) indicate the amount of variance explained by the moderator (Snijders \& Bosker, 2012). The procedure was repeated for each moderator and applies to moderators at level 1 as well as moderators at level 2 (Snijders \& Bosker, 2012).

\section{RESULTS}

Table 2 summarizes the results of the two-level model outlined in the statistical analyses section. A narrative of the central results follows. To begin with, we obtained a positive effect of agency on self-esteem and a positive effect of communion on self-esteem. ${ }^{2}$

These two main effects were uniquely qualified by culture. A positive individual-level agency $\times$ culture-level agency cross-level interaction showed that the effect of agency on selfesteem increased with rising culture-level agency. A positive individual-level communion $\times$ culture-level communion cross-level interaction showed that the effect of communion on selfesteem increased with rising culture-level communion. Thus, the effects of agency and communion on self-esteem varied by culture. Nonetheless, following decomposition of these cross-level interactions, the effects of agency and communion on self-esteem remained positive in all cultures (despite varying in size, as indicated by the cross-level interactions). 
The two main effects were also uniquely qualified by personal religiosity. A negative agency $\times$ religiosity interaction showed that the effect of agency on self-esteem decreased with rising religiosity. Furthermore, a positive communion $\times$ religiosity interaction showed that the effect of communion on self-esteem increased with rising religiosity. Thus, the effects of agency and communion on self-esteem varied by individual-level religiosity. Nonetheless, when decomposing these interactions, we found that all simple slopes were positive and significant at $p<.001$ (despite varying in steepness, as indicated by the interactions).

In addition, the two main effects were uniquely qualified by sex (women were coded as " 0 ," men as " 1 "). A positive agency $\times$ sex interaction showed that the effect of agency on self-esteem was stronger among men. A negative communion $\times$ sex interaction showed that the effect of communion on self-esteem was stronger among women. Thus, the effects of agency and communion on self-esteem varied by sex. Yet, following interaction decomposition, the effects of agency and communion on self-esteem remained positive and significant for both sexes at $p<.001$ (despite varying in size, as indicated by the interactions).

Finally, the two main effects were uniquely qualified by age. A negative agency $\times$ age interaction showed that the effect of agency on self-esteem decreased with rising age. However, a positive communion $\times$ religiosity interaction showed that the effect of communion on self-esteem increased with rising age. Thus, the effects of agency and communion on self-esteem varied by participant age. Nevertheless, following interaction decomposition, all simple slopes were positive and significant at $p<.001$ (despite varying in size, as indicated by the interactions).

In summary, agency and communion were both related to self-esteem. Crucially, agency effects and communion effects were both moderated by culture-level agency and communion, personal religiosity, sex, and age. Given that we obtained these moderations in a single model, each effect occurred over and above the other three effects. These result patterns provide strong evidence for the unique influence of the moderators. Regardless, we proceeded to repeat all analyses separately for each moderator and obtained similar results.

A remaining question concerns the relative influence of each moderator. Are all four moderators similarly influential or do they differ in their moderating strength? To address this 
question, we performed analyses of the proportion of variance in self-esteem explained by each moderator (see Statistical Analyses section). Results revealed clear differences in moderator impact. Culture explained $13 \%$ of the variance, followed by sex, which explained $3 \%$. Religiosity and age explained 1\% each. These results are in line with TMT (Greenberg, 1997), which ascribes culture a particularly influential role in the formation of what a person will regard as self-central (Pyszczynski et al., 2004). ${ }^{3}$

These differentially strong moderating effects notwithstanding, Figure 1 illustrates the collective influence of the four moderators on the relation between agency-communion and self-esteem. The left panel shows the relations between agency-communion and self-esteem among individuals for whom agency should be most self-central: Younger ( $\leq 30$ years), nonreligious (score $\leq 2$ ) men from Poland (which featured the highest culture-level agency, relative to communion). Within this group, the relation between agency and self-esteem, $\beta=$ $.69, p<.001$, was particularly strong compared to the relation between communion and selfesteem, $\beta=.20, p<.001$. The middle panel shows the same relations within the full sample (no selection criteria applied). Overall, the relation between agency and self-esteem, $\beta=.49, p$ $<.001$, was stronger than the relation between communion and self-esteem, $\beta=.36, p<.001$. Finally, the right panel shows these relations among individuals for whom communion should be most self-central: Older ( $\geq 60$ years), religious (score $\geq 6$ ) women from Germany (which featured the highest culture-level communion, relative to agency). Within this group, the relation between communion and self-esteem, $\beta=.54, p<.001$, was stronger than the relation between agency and self-esteem, $\beta=.38, p<.001$.

\section{Discussion}

Agency-communion and self-esteem are essential constructs in many areas of psychology. But how are they interrelated? The literature is scarce, indirect, and inconsistent. One line of research points to a positive relation between agency and self-esteem (Wojciszke et al., 2011). Another research line indicates a positive relation between communion and selfesteem (DeYoung, 2006). And a third line of research suggests positive relations of both agency and communion to self-esteem (Zeigler-Hill, 2010).

\section{Summary of Findings}


Aiming to clarify this confusing state of knowledge, we took what is arguably a nuanced and flexible perspective. Our perspective built on William James's (1907) theorizing in articulating the self-centrality breeds self-enhancement principle (Harter, 1993; Sedikides \& Strube, 1997; Tesser \& Campbell, 1983). Based on this principle, we hypothesized and found that agency is related to higher self-esteem if agency is self-central, whereas communion is related to higher self-esteem if communion is self-central.

We implemented the following four indicators of high agentic self-centrality: high culture-level agency (Pyszczynski et al., 2004), low personal religiosity (Bakan, 1966), maleness (Bem, 1967), and younger age (Charles \& Carstensen, 2010). Conversely, we implemented the following four indicators of high communal self-centrality: high culturelevel communion, high personal religiosity, femaleness, and older age. Results supported the unique influence of these moderators on the relation between agency-communion and selfesteem. The results provided strong support for the self-centrality breeds self-enhancement principle, and for its applicability to fundamental personality dimensions in particular.

\section{Limitations}

These findings notwithstanding, the current research has several limitations. First, we used an existing dataset, which unfortunately does not include explicit measures of selfcentrality, personal standards, or personal importance. We sought to counter this limitation by selecting four moderators that are well known for their strong links to agentic and communal self-centrality, and all four moderators yielded theory-supportive results. Nonetheless, direct assessment of self-centrality is a priority for future research: it is possible that each moderator-effect was driven by different processes (i.e., processes other than self-centrality breeds self-enhancement). Nevertheless, in the absence of empirical evidence for such specificity, the law of parsimony (Batting, 1962) calls for adherence to a single, unifying process, and the self-centrality breeds self-enhancement principle constitutes such a process.

Second, although all moderators supported the self-centrality breeds self-enhancement principle, culture-level agency and communion explained considerably more variance $(13 \%)$ than sex $(3 \%)$, religiosity $(1 \%)$, and age $(1 \%)$. These results are consistent with TMT (Greenberg et al., 1997), which ascribes culture an influential role in the formation of self- 
central standards. From the perspective of the self-centrality breeds self-enhancement principle, differences in the explained variance between moderators is due to the differential importance of these moderators in the formation of self-central standards. Thus, the differential moderating impact of culture, sex, religiosity, and age could be parsimoniously explained by the self-centrality breeds self-enhancement principle, if the values imposed by culture had on average more impact on self-central standards than the values imposed by sex, religiosity, and age (in this rank-order). A direct measure of self-centrality would have allowed to test whether this intuitively plausible rank-order of moderators applied. This reasoning strengthens the call for research using direct measures of self-centrality.

Third, the uncovered moderation by age is consistent with past theory and research, which indicates that communion becomes more important, whereas agency becomes less important, with age (Charles \& Carstensen, 2010; Zeigler-Hill, 2010). However, this pattern may also be due to cohort effects. Indeed, evidence suggests that the importance of agency has increased over the last decades (Twenge, Konrath, Foster, Campbell, \& Bushman, 2008), whereas the importance of communion has decreased within this time-frame (Konrath, O’Brien, \& Hsing, 2011; Twenge, Campbell, \& Freeman, 2012). Longitudinal studies are needed to test the personality development explanation against the cohort effect explanation.

Fourth, the present dataset is limited to eleven Western cultures. Thus, it remains unclear whether the findings extend to cultures such as East-Asia. On the one hand, our sole focus on Western cultures should have led to a restriction in between-culture variances of agency and communion. For example, East-Asian cultures are most communal, but were not represented in the dataset. Given that such variance restriction lowers effect sizes, inclusion of non-Western cultures would lead to stronger effect sizes. On the other hand, self-reported self-esteem may be tainted by modesty concerns in East-Asian cultures (Cai et al., 2011; Hepper, Sedikides, \& Cai, in press). Given that such modesty bias compromises the validity of self-reported self-esteem, inclusion of non-Western cultures would decrease effect sizes.

Finally, we constructed measures of agency, communion, self-esteem, and religiosity capitalizing on the eDarling dataset. We garnered convergent evidence for the validity of these measures: (a) we ensure the items were face valid, (b) we conducted additional 
validation studies to ensure that the measures were highly related to established scales, and (c) we replicated standard findings within the eDarling dataset (Gebauer et al., 2012b, in press-a, in press-b, in press-c). Nonetheless, it would be desirable to replicate our results with more established measures of agency, communion, self-esteem, and religiosity.

\section{Implications}

Despite these limitations, the findings are informative for cross-cultural psychology, the psychology of religion, sex differences, and life-span psychology. Regarding crosscultural psychology, our research dovetails with prior evidence that self-esteem contingencies are not culturally universal (Diener \& Diener, 1995). These cultural differences notwithstanding, our research does point towards cultural universality of the self-centrality breeds self-enhancement principle (Sedikides \& Gregg, 2008). Regarding the psychology of religion, the present research illustrates the influence religion can have on basic psychological processes such as the personality--self-esteem link. This reinforces calls for intensifying empirical efforts on the correlates, causes, and implications of religiosity (Sedikides, 2010). It also underscores that religiosity encourages communion, while discouraging some forms of agency (Bakan, 1966). Regarding sex, our research further suggests that men (still) value agency more, whereas women (still) value communion more (Eagly \& Wood, 1999), and that these sex differences are not due to sex differences in culture-level agency-communion, religiosity, or age. Finally, regarding age, our research accords with the assumption of lifespan psychology that valuing communion over agency constitutes the key developmental task of the aging self (Charles \& Carstensen, 2010). Labouvie-Vief (1994) argued that older adults may be able to maintain positive functioning when this developmental task is achieved, and our research points towards one mechanism for achieving this task.

The specific sources of self-centrality documented in the current research may help reconcile inconsistencies in the literature on agency-communion and self-esteem. For example, Wojciszke et al. (2011) conducted an important test of the relation between agencycommunion and self-esteem, and they found very low correlations between communion and self-esteem (with the exception of older state clerks, for whom communion was moderately related to self-esteem). Why would this be the case, considering that caring for and nurturing 
others (the core of communion) boosts psychological health - a strong correlate of self-esteem (Brown, Nesse, Vinokur, \& Smith, 2003)? Wojciszke et al.'s cultural setting may provide an explanation. Their studies were all conducted in Poland - precisely the country that featured the lowest culture-level communion (relative to agency) in the present dataset (Figure 1).

Having said that, we hasten to add that the present research does not contradict what Wojciszke et al. (2011) set out to test: their double perspective model (DPM). According to the DPM, global self-evaluations are tied to one's own agency level, whereas global otherevaluations are tied to others' communion level. As such, global self-evaluations may serve as an affective-motivational gauge of one's agency-level, whereas global other-evaluations may serve as an affective-motivational gauge of others' communion-level (Kirkpatrick \& Ellis, 2001). In fact, the evolutionary emergence of such affective-motivational gauges is a distinct possibility. Being personally high on self-profitable traits (i.e., agency; Peeters, 1992), while simultaneously surrounding oneself with others who are high on other-profitable traits (i.e., communion; Peeters, 1992), appears evolutionarily paramount, because in this way one gains optimal survival and reproductive benefits from both self and others.

Relatedly, Wojciszke et al. (2011) stated: "we do not assume that people completely ignore communal information when forming their self-esteem —we only assume that their self-esteem is more driven by agentic than communal considerations" (p. 618). Inspection of the middle panel of Figure 1 (i.e., full sample) reveals that the present results fits this assumption: Overall, agency and communion are both linked to self-esteem, but agency is more strongly linked to self-esteem than is communion. Nonetheless, inspection of the left and right panels of Figure 1 shows that the relations between agency-communion and selfesteem vary considerably as a function of our four moderators. Evidently, the DPM is not sufficient to account fully for the relation between agency-communion and self-esteem. Indeed, the obtained results are best—and sufficiently_explained by the combined workings of the DPM and the self-centrality breeds self-enhancement principle.

The present results are also informative for the interpersonal circumplex literature. This framework arranges interpersonal traits (e.g., dominant, kind to others) on a circumplex structure spanned by two orthogonal dimensions, which correspond to agency and 
communion (Wiggins, 1991). Early advocates of this framework (Leary, 1957; Sullivan 1953) assumed that the desire to increase self-esteem motivates self-profitable interpersonal behavior (which corresponds to agency_Peeters, 1992) and other-profitable interpersonal behavior (which corresponds to communion-Peeters, 1992). Overall, our results are in line with this assumption, but suggest that any given interpersonal behavior leads to considerable increases in self-esteem, provided the behavior is self-central. This should be the case for selfprofitable/agentic and for other-profitable/communal interpersonal behaviors.

A typical finding in the literature is that people rate themselves as higher on communal than on agentic traits (Abele \& Wojciszke, 2007; Schwartz \& Bardi, 2001; Sedikides, 1993), and the same pattern also emerged in all countries of the present sample, all $t \mathrm{~s}>127.37, d f \mathrm{~s}>$ $13,898, p \mathrm{~s}<.001$. Past research has explained this finding in terms of motivated selfenhancement bias (Van Lange \& Sedikides, 1998). However, if self-enhancement motivation alone drove these effects, one would generally expect stronger relations between communion and self-esteem (compared to relations between agency and self-esteem). Yet, past (Wojciszke et al., 2011) and present (Figure 1) evidence shows that the reverse is the case: agency is more strongly related to self-esteem. This suggests that factors other than motivated self-enhancement bias may lead to higher self-ratings on communion than on agency. Cognitive factors are a possible candidate. Communal traits may be broader, more overlapping with each other, and fuzzier than agentic traits. These properties of communal traits would make it easier to generate a larger number of exemplifying behaviors (Bless \& Schwarz, 2010). Further, the ease with which exemplar behaviors were generated would precipitate an increase in self-ratings (Schwarz et al., 1991).

We would like to explicate further the relevance of the self-centrality breeds selfenhancement principle for the relation between agency-communion and self-esteem. Personality and self-esteem are among the most basic and most genetically grounded traits (Neiss, Sedikides, \& Stevenson, 2006; Neiss et al., 2009). Thus, static and hard-wired relations between these traits could have been a distinct possibility. Considering this, our research illustrates the wide-ranging scope of the self-centrality breeds self-enhancement principle across cultures, personal religiosity, sex, and age. As such, the research suggests that 
this principle is fundamental and universal, thus inviting speculation about its evolutionary origins (Sedikides \& Skowronski, 1997; Sedikides, Skowronski, \& Dunbar, 2006). For example, humans may have been motivated to invest resources (i.e., time, effort) in the pursuit of self-central standards. At the proximal level, the pursuit of such standards promises the attainment of self-esteem, with all its positive emotional consequences (Alicke \& Sedikides, 2009; Sedikides, Gregg, \& Hart, 2007). At the distal level, the pursuit of selfcentral standards promises the attainment of group or social inclusion (Gebauer, Göritz, Hofmann, \& Sedikides, in press; Leary \& Baumeister, 2000), given that self-centrality is often rooted in the values of one's social surrounding (Bernard, Gebauer, \& Maio, 2006).

\section{Concluding Remarks}

The reported research examines the relation between agency-communion and selfesteem. Despite the relevance of these constructs, past research has been sparse, often indirect, and inconsistent. We relied on William James's (1907) theorizing to offer the selfcentrality breeds self-enhancement principle, in an attempt to clarify inconsistencies in the literature. We hypothesized that the relation between agency and self-esteem will increase with rising self-centrality of agency (operationalized as high culture-level agency, low personal religiosity, maleness, and younger age). Conversely, we hypothesized that the relation between communion and self-esteem will increase with rising self-centrality of communion (operationalized as high culture-level communion, high personal religiosity, femaleness, and older age). Our hypotheses were supported in a sample of 187,957 individuals across 11 cultures. The findings paint a nuanced picture of the relation between agency-communion and self-esteem while highlighting the universality of the self-centrality breeds self-enhancement principle. 


\section{References}

Abele, A. E., \& Bruckmüller, S. (2011). The bigger one of the 'Big Two' Preferential processing of communal information. Journal of Experimental Social Psychology, 47, 935-948.

Abele, A. E., Uchronski, M., Suitner, C. \& Wojciszke, B. (2008). Towards an operationalization of the fundamental dimensions of agency and communion: Trait content ratings in five countries considering valence and frequency of word occurrence. European Journal of Social Psychology, 38, 1202-1217.

Abele, A. E., \& Wojciszke, B. (2007). Agency and communion from the perspective of self versus others. Journal of Personality and Social Psychology, 9, 751-763.

Alicke, M. D., \& Sedikides, C. (2009). Self-enhancement and self-protection: What they are and what they do. European Review of Social Psychology, 20, 1-48.

Alicke, M. D., \& Sedikides, C. (2011). Handbook of self-enhancement and self-protection. New York, NY: Guilford Press.

Allison, S. T., Messick, D. M., \& Goethals, G. R. (1989). On being better but not smarter than others: The Mohammad Ali effect. Social Cognition, 7, 275-295.

Bakan, D. (1966). The duality of human existence: Isolation and communion in Western man. Boston, MA: Beacon Press.

Battig, W. F. (1962). Parsimony in psychology. Psychological Reports, 11, 555-572.

Batson, C. D., Schoenrade, P. A., \& Ventis, W. L. (1993). Religion and the individual: A social-psychological perspective. New York, NY: Oxford University Press.

Bernard, M., Gebauer, J. E., \& Maio, G. R. (2006). Cultural estrangement: The role of personal and societal value discrepancies. Personality and Social Psychology Bulletin, 32, 78-92.

Bem, S. (1974). The measurement of psychological androgyny. Journal of Consulting and Clinical Psychology, 42, 155-162.

Benet, V., \& Waller, N. G. (1995). The "Big Seven" model of personality description: Evidence for its cross-cultural generality in a Spanish sample. Journal of Personality and Social Psychology, 69, 701-718. 
Bless, H., \& Schwarz, N. (2010). Mental construal and the emergence of assimilation and contrast effects: The Inclusion/Exclusion Model. Advances in Experimental Social Psychology, 42, 319-373.

Bollen, K. A., \& Curran, P. J. (2006). Latent curve models. A structural equation perspective. Hoboken, New Jersey: Wiley.

Brown, J. D. (2012). Understanding the better than average effect: Motives (still) matter. Personality and Social Psychology Bulletin, 38, 209-219.

Brown, S. L., Nesse, R. M., Vinokur, A., \& Smith, D. M. (2003). Providing social support may be more beneficial than receiving it: Results from a prospective study of mortality. Psychological Science, 14, 320-327.

Bushman, B. J., Moeller, S. J., \& Crocker, J. (2011). Sweets, sex, or self-esteem? Comparing the value of self-esteem boosts with other pleasant rewards. Journal of Personality, 79, 993-1012.

Cai, H., Sedikides, C., Gaertner, L., Wang, C., Carvallo, M., Xu, Y., O’Mara, E. M., \& Jackson, L. E. (2011). Tactical self-enhancement in China: Is modesty at the service of self-enhancement in East-Asian culture? Social Psychological and Personality Science, 2, 59-64.

Campbell, W. K., Rudich, E., \& Sedikides, C. (2002). Narcissism, self-esteem, and the positivity of self-views: Two portraits of self-love. Personality and Social Psychology Bulletin, 28, 358-368.Charles, S. T., \& Carstensen, L. L. (2010). Social and emotional aging. Annual Review of Psychology, 61, 383-409.

Cheng, C., Jose, P. E., Sheldon, K. M., Singelis, T. M., Cheung, M.W.L., ..., \& Sims, C. (2011). Sociocultural differences in self-construal and subjective well-being: A test of four cultural models. Journal of Cross-Cultural Psychology, 42, 832-855.

Cheung, G. W., \& Rensvold, R. B. (2002). Evaluating goodness-of-fit indexes for testing measurement invariance. Structural Equation Modeling, 9, 233-255.

Coopersmith, S. (1967). The antecedents of self-esteem. San Francisco, CA: W. H. Freeman.

Crocker, J., \& Wolfe, C. T. (2001). Contingencies of self-worth. Psychological Review, 108, 593-623. 
Diener, E., \& Diener, M. (1995). Cross-cultural correlates of life satisfaction and self-esteem. Journal of Personality and Social Psychology, 68, 653-663.

Diener, E., Tay, L., \& Myers, D. G. (2011). The religion paradox: If religion makes people happy, why are so many dropping out? Journal of Personality and Social Psychology, $101,1278-1290$.

DuBois, D. L., \& Flay, B. R. (2004). The healthy pursuit of self-esteem: Comment on and alternative to the Crocker and Park (2004) formulation. Psychological Bulletin, 130, 415-420.

Eagly, A. H., \& Wood, W. (1999). The origins of sex differences in human behavior. American Psychologist, 54, 408-423.

Erikson, E. H. (1982). The life cycle completed: A review. New York, NY: Norton \& Company.

Fiske, A. P. (2002). Using individualism and collectivism to compare cultures - a critique of the validity and measurement of the constructs: Comment on Oyserman et al. (2002). Psychological Bulletin, 128, 78-88.

Fiske, S. T., Cuddy, A. J. C., Glick, P., \& Xu, J. (2002). A model of (often mixed) stereotype content: Competence and warmth respectively follow from status and competition. Journal of Personality and Social Psychology, 82, 878-902.

Fung, H. H., \& Carstensen, L. L. (2003). Sending memorable messages to the old: Age differences in preferences and memory for advertisements. Journal of Personality and Social Psychology, 85, 163-178.

Gaertner, L., Sedikides, C., \& Chang, K. (2008). On pancultural self-enhancement: Welladjusted Taiwanese self-enhance on personally-valued traits. Journal of CrossCultural Psychology, 39, 463-477.

Gebauer, J. E., Göritz, A. S., Hofmann, W., \& Sedikides, C. (in press). Self-love or other love? Explicit other-preference but implicit self-preference. PLOS ONE.

Gebauer, J. E., Leary, M. R., \& Neberich, W. (in press-a). Unfortunate first-names: Effects of name-based relational devaluation and interpersonal neglect. Social Psychological and Personality Science. 
Gebauer, J. E., Leary, M. R., \& Neberich, W. (in press-b). Big Two personality and Big Three mate preferences: Similarity attracts, but country-level mate preferences crucially matter. Personality and Social Psychology Bulletin.

Gebauer, J. E., Lei, X., Cai, H., Gaertner, L. \& Sedikides, C. (2012a). Communal selfenhancement in China. Unpublished manuscript. Humboldt-Universität zu Berlin.

Gebauer, J. E., \& Maio, G. R. (2012). The need to belong can motivate belief in God. Journal of Personality, 80, 465-501.

Gebauer, J. E., Paulhus, D. L., \& Neberich, W. (in press-c). Big Two personality and religiosity across cultures: Communals as religious conformists and agentics as religious contrarians. Social Psychological and Personality Science.

Gebauer, J. E., Sedikides, C., \& Neberich, W. (2012b). Religiosity, social self-esteem, and psychological adjustment: On the cross-cultural specificity of the psychological benefits of religiosity. Psychological Science, 23, 158-160.

Greenberg, J., Solomon, S., \& Pyszczynski, T. (1997). Terror management theory of selfesteem and cultural worldviews: Empirical assessments and cultural refinements. In M. Zanna (Ed.), Advances in experimental social psychology (Vol. 29, pp. 61-139). San Diego, CA: Academic Press.

Harter, S. (1993). Causes and consequences of low self-esteem in children and adolescents. In R. F. Baumeister (ed.), Self-esteem: The puzzle of low self-regard (pp. 87-116). New York, NY: Plenum.

Heatherton, T. F., \& Polivy, J. (1991). Development and validation of a scale for measuring state self-esteem. Journal of Personality and Social Psychology, 60, 895-910.

Hepper, E. G., Sedikides, C., \& Cai, H. (in press). Self-enhancement and self-protection strategies in China: Cultural expressions of a fundamental human motive. Journal of Cross-Cultural Psychology.James, W. (1907). The principles of psychology. Vol. 1. New York, NY: Holt.

Janis, I. L., \& Field, E. B. (1959). Sex differences and factors related to persuasibility. In C. I. Hovland \& I. L. Janis (Eds.), Personality and persuasibility (pp. 55-68). New Haven, CT: Yale University Press. 
Jensen, A. R. (1998). The g factor: The science of mental ability. Westport, CT: Praeger.

John, O. P., \& Srivastava, S. (1999). The Big Five Trait taxonomy: History, measurement, and theoretical perspectives. In L. A. Pervin \& O. P. John (Eds.), Handbook of personality: Theory and research (2nd ed., pp. 102-139). New York, NY: Guilford Press.

Judge, T. A., Erez, A., Bono, J. E., \& Thoresen, C. J. (2002). Are measures of self-esteem, neuroticism, locus of control, and generalized self-efficacy indicators of a common core construct? Journal of Personality and Social Psychology, 83, 693-710.

Kirkpatrick, L. A., \& Ellis, B. J. (2001). An evolutionary approach to self-esteem: Multiple domains and multiple functions. In M. Clark \& G. Fletcher (Eds.), The Blackwell handbook of social psychology (Vol. 2, pp. 411-436). Oxford, UK: Basil Blackwell.Koenig, H. G., Meador, K., \& Parkerson, G. (1997). Religion Index for psychiatric research: A 5-item measure for use in health outcome studies. American Journal of Psychiatry, 154, 885-886.

Labouvie-Vief, G. (1994). Psyche and Eros: Mind and gender in the life course. New York, NY: Cambridge University Press.

Lang, F. R., \& Carstensen, L. L. (2002). Time counts: Future time perspective, goals, and social relationships. Psychology and Aging, 17, 125-139.

Leary, M. R., \& Baumeister, R. F. (2000). The nature and function of self-esteem: Sociometer theory. Advances in Experimental Social Psychology, 32, 1-62.

Leary, T. (1957). Interpersonal diagnosis of personality: A functional theory and methodology for personality evaluation. New York: Ronald.

Markus, H. R., \& Kitayama, S. (1991). Culture and the self: Implications for cognition, emotion, and motivation. Psychological Review, 20, 568-579.

Murray, S. L., Holmes, J. G., \& Griffin, D. W. (2000). Self-esteem and the quest for felt security: how perceived regard regulates attachment processes. Journal of Personality and Social Psychology, 78, 478-498.

Musek, J. (2007). A general factor of personality: Evidence for the Big One in the five-factor model. Journal of Research in Personality, 41, 1213-1233. 
Neiss, M. B., Stevenson, J., Legrand, L.N., Iacono, W. G., \& Sedikides, C. (2009). Selfesteem, negative emotionality, and depression as a common temperamental core: A study of mid-adolescent twin girls. Journal of Personality, 77, 327-346.

Neiss, M. B., Sedikides, C., \& Stevenson, J. (2006). Genetic influences on level and stability of self-esteem. Self and Identity, 5, 247-266.

Neiss, M. B., Stevenson, J., Sedikides, C., Kumashiro, M., Finkel, E., J., \& Rusbult, C. E. (2005). Executive self, self-esteem, and negative affectivity: Relations at the phenotypic and genotypic level. Journal of Personality and Social Psychology, 89, 593-606.

Oyserman, D., Coon, H. M., \& Kemmelmeier, M. (2002). Rethinking individualism and collectivism: evaluation of theoretical assumptions and meta-analyses. Psychological Bulletin, 128, 3-72.

Paulhus, D. L., \& John, O. P. (1998). Egoistic and moralistic bias in self-perceptions: The interplay of self-deceptive styles with basic traits and motives. Journal of Personality, 66, 1025-1060.

Peeters, G. (1992). Evaluative meanings of adjectives in vitro and in context: Some theoretical implications and practical consequences of positive negative asymmetry and behavioral-adaptive concepts of evaluation. Psychologia Belgica, 32, 211-231.

Pyszczynski, T., Greenberg, J., Solomon, S., Arndt, J., \& Schimel, J. (2004). Why do people need self-esteem?: A theoretical and empirical review. Psychological Bulletin, 130, 435-468.

Raudenbush, S. W. (1989). “Centering” predictors in multilevel analysis: Choices and consequences. Multilevel Modelling Newsletter, 1, 10-12.

Raudenbush, S. W., Bryk, T., \& Congdon, R. (2004). HLM for Windows (Version 6.06) [Computer software]. Lincolnwood, IL: Scientific Software International.

Robins, R. W., Tracy, J. L., Trzesniewski, K. H., Potter, J., \& Gosling, S. D. (2001). Personality correlates of self-esteem. Journal of Research in Personality, 35, 463-482.

Rosenberg, M. (1965). Society and the adolescent self-image. Princeton, NJ: Princeton University Press. 
Routledge, C., Ostafin, B., Juhl, J., Sedikides, C., Cathey, C., \& Liao, T. (2010). Adjusting to death: The effects of mortality salience and self-esteem on psychological well-being, growth motivation, and maladaptive behavior. Journal of Personality and Social Psychology, 99, 897-916.

Saucier, G. (2009). What are the most important dimensions of personality? Evidence from studies of descriptors in diverse languages. Social and Personality Psychology Compass, 3/4, 620-637.

Schmitt, D. P. (2005). Sociosexuality from Argentina to Zimbabwe: A 48-nation study of sex, culture, and strategies of human mating. Behavioral and Brain Sciences, 28, 247-275.

Schmitt, D. P., \& Allik, J. (2005). Simultaneous administration of the Rosenberg Self-Esteem Scale in 53 nations: Exploring the universal and culture-specific features of global self-esteem. Journal of Personality and Social Psychology, 89, 623-642.

Schwartz, S. H., \& Bardi, A. (2001). Value hierarchies across cultures: Taking a similarities perspective. Journal of Cross-Cultural Psychology, 32, 268-290.

Schwarz, N., Bless, H., Strack, F., Klumpp, G., Rittenauer-Schatke, H., \& Simons, A. (1991). Ease of retrieval as information: Another look at the availability heuristic. Journal of Personality and Social Psychology, 61, 195-202.

Sedikides, C. (1993). Assessment, enhancement, and verification determinants of the selfevaluation process. Journal of Personality and Social Psychology, 65, 317-338.

Sedikides, C. (2010). Why does religiosity persist? Personality and Social Psychology Review, 14, 3-6.

Sedikides, C., Gaertner, L., \& Toguchi, Y. (2003). Pancultural self-enhancement. Journal of Personality and Social Psychology, 84, 60-79.

Sedikides, C., Gaertner, L., \& Vevea, J. (2005). Pancultural self-enhancement reloaded: A meta-analytic reply to Heine (2005). Journal of Personality and Social Psychology, $89,531-551$.

Sedikides, C., \& Gebauer, J. E. (2010). Religiosity as self-enhancement: A meta-analysis of the relation between socially desirable responding and religiosity. Personality and Social Psychology Review, 14, 17-36. 
Sedikides, C., \& Gebauer, J. E. (in press). Religion and the self. In V. Saroglou (Ed.), Religion, personality, and social behavior. New York, NY: Psychology Press.

Sedikides, C., \& Gregg, A. P. (2003). Portraits of the self. In M. A. Hogg \& J. Cooper (Eds.), Sage handbook of social psychology (pp. 110-138). London, England: Sage Publications.

Sedikides, C., \& Gregg, A. P. (2008). Self-enhancement: Food for thought. Perspectives on Psychological Science, 3, 102-116.

Sedikides, C., Gregg, A. P., \& Hart, C. M. (2007). The importance of being modest. In C. Sedikides \& S. Spencer (Eds.), The self: Frontiers in social psychology (pp. 163-184). New York, NY: Psychology Press.

Sedikides, C., Rudich, E. A., Gregg, A. P., Kumashiro, M., \& Rusbult, C. (2004). Are normal narcissists psychologically healthy? Self-esteem matters. Journal of Personality and Social Psychology, 87, 400-416.

Sedikides, C., \& Skowronski, J. A. (1997). The symbolic self in evolutionary context. Personality and Social Psychology Review, 1, 80-102.

Sedikides, C., Skowronski, J. J., \& Dunbar, R. I. M. (2006). When and why did the human self evolve? In M. Schaller, J. A. Simpson, \& D. T. Kenrick (Eds.), Evolution and social psychology: Frontiers in social psychology (pp. 55-80). New York, NY: Psychology Press.

Sedikides, C., \& Strube, M. J. (1997). Self-evaluation: To thine own self be good, to thine own self be sure, to thine own self be true, and to thine own self be better. Advances in Experimental Social Psychology, 29, 209-269. New York, NY: Academic Press.

Singelis, T. M., Bond, M. H., Sharkey, W. F., \& Siu Yiu Lai, C. (1999). Unpacking culture's influence on self-esteem and embarrassability. Journal of Cross-Cultural Psychology, 30, 315-341.

Sheldon, K. M., Elliot, A. J., Kim, Y., \& Kasser, T. (2001). What is satisfying about satisfying events? Testing 10 candidate psychological needs. Journal of Personality and Social Psychology, 80, 325-339. 
Snijders, T. A. B., \& Bosker, R. J. (2012). Multilevel analysis. An introduction to basic and advanced multilevel modeling ( $2^{\text {nd }}$ edition). London: Sage Publishers.

Sullivan, H. S. (1953). The interpersonal theory of psychiatry. New York: Norton.

Tesser, A. (2000). On the confluence of self-esteem maintenance mechanisms. Personality and Social Psychology Review, 4, 290-299.

Tesser, A., \& Campbell, J. (1980). Self-definition: The impact of the relative performance and similarity of others. Social Psychology Quarterly, 43, 341-347.

Thompson, E. R., \& Phua, F. T. T. (2005). Are national cultural traits applicable to senior firm managers? British Journal of Management, 16, 59-68.

Trapnell, P. D., \& Paulhus, D. L. (2012). Agentic and communal values: Their scope and measurement. Journal of Personality Assessment, 94, 39-52.

Twenge, J. M., Campbell, W. K., \& Freeman, E. C. (2012). Generational differences in young adults' life goals, concern for others, and civic orientation, 1966-2009. Journal of Personality and Social Psychology, 102, 1045-1062.

Twenge, J. M., Konrath, S., Foster, J. D., Campbell, W. K., \& Bushman, B. J. (2008). Egos inflating over time: A cross-temporal meta-analysis of the Narcissistic Personality Inventory. Journal of Personality, 76, 875-901.

Uusitalo, A. L., Vanninen, E., Levalahti, E., Battie, M. C., Videman, T., \& Kaprio, J. (2007). Role of genetic and environmental influences on heart rate variability in middle-aged men. American Journal of Physiology: Heart and Circulatory Physiology, 293, H1013-H1022.

Van Lange, P. A. M., \& Sedikides, C. (1998). Being honest but not necessarily more intelligent than others: Generality and explanations for the Muhammad All effect. European Journal of Social Psychology, 28, 675-680.

Verplanken, B., \& Holland, R. W. (2002). Motivated decision making: Effects of activation and self-centrality of values on choices and behavior. Journal of Personality and Social Psychology, 82, 434-447. 
Wagner, J., Lüdtke, O., Jonkmann, K., \& Trautwein, U. (in press). Cherish yourself: Longitudinal patterns and conditions of self-esteem change in the transition to young adulthood. Journal of Personality and Social Psychology.

Wiggins, J. S. (1991). Agency and communion as conceptual coordinates for the understanding and measurement of interpersonal behavior. In W. M. Grove \& D. Ciccetti (Eds.), Thinking clearly about psychology: Vol. 2. Personality and psychopathology (pp. 89-113). Minneapolis, MN: University of Minnesota Press.

Wiggins, J. S. (1995). Interpersonal adjective scales professiosnal manual. Odessa, FL: Psychological Assessment Resources.

Wiggins, J. S., \& Trapnell, P. D. (1996). A dyadic-interactional perspective on the five factor model. In J. S. Wiggins (Ed.), The five-factor model of personality: Theoretical perspectives (pp. 88-162). New York, NY: Guilford.

Wojciszke, B. (1997). Parallels between competence- versus morality-related traits and individualistic versus collectivistic values. European Journal of Social Psychology, $27,245-256$.

Wojciszke, B., Baryla, W., Parzuchowski, M., Szymkow, A., \& Abele, A. E. (2011). Selfesteem is dominated by agentic over communal information. European Journal of Social Psychology, 40, 1-11.

Wrzus, C., Köckeritz, M., Wagner, J., \& Neyer, F. J. (in press). Social network change and life events across the lifespan: A meta-analysis. Psychological Bulletin.

Zeigler-Hill, V. (2010). The interpersonal nature of self-esteem: Do different measures of self-esteem possess similar interpersonal content? Journal of Research in Personality, $44,22-30$. 
Footnotes

${ }^{1}$ We do not mean to imply that the obtained scores are necessarily representative of the 11 countries at large. It is possible that eDarling participants constitute specific (and possibly different) subcultures within each country (Gebauer et al., in press-b). Nevertheless, sampling of subcultures within countries is frequent in psychology. To illustrate, Oyserman, Coon, and Kemmelmeier (2002) compared mean levels of individualism and collectivism between studies. They obtained large mean differences between different studies within the same country, suggesting that different subcultures were sampled within the same country. Thus, to obtain suitable (sub)culture-level indices for a given sample, it is most appropriate to average individual-scores from this sample (Fiske, 2002; Schmitt, 2005). This reasoning mirrors the applicability of Hofstede's culture-level indices. He averaged individual-level responses from 'average employee samples' to obtain culture-level indices. These indices are psychologically relevant for "average" employees, but psychologically irrelevant for senior executives

(Thompson \& Phua, 2005). Irrespective, the eDarling based culture-level agency-communion indices were psychologically relevant for the present eDarling participants.

${ }^{2}$ The finding that agency and communion showed independent and substantial main effects on self-esteem is consistent with theory (Leary, 1957; Sullivan, 1953) and research (ZeiglerHill, 2010) on the interpersonal circumplex. Specifically, one of the interpersonal circumplex's octants ("gregarious-extraverted") captures simultaneously high agency and high communion (Wiggins, 1991), and this octant is the one that is most strongly linked to high global self-esteem at theoretical (Leary, 1957; Sullivan, 1953) and empirical (Zeigler-Hill, 2010) level. What predictions, however, does interpersonal theory make regarding a possible interaction between agency and communion on self-esteem? To the best of our knowledge, interpersonal theory is mute to this question, while assuming that individuals simultaneously low on agency and low on communion possess the lowest self-esteem, whereas individuals high on agency and high on communion possess the highest self-esteem, and the two high-low 
combinations fall in between. Thus, we explored whether agency and communion interact in predicting self-esteem. We ran a new HLM model, which was identical to the model outlined in the Data Analyses section, with the exception that we added the interaction between agency and communion (group-mean centered). This interaction was significant, but, when decomposing it, we found that the pattern of the two main effects was hardly qualified. If anything, the interaction indicated a slightly reduced self-esteem effect for participants high on agency and high on communion, and this reduction may be best explained by a ceiling effect. Irrespective, and in full agreement with interpersonal theory, those participants scored highest on self-esteem, followed by participants high on agency and low on communion, which were followed by participants low on agency and high on communion, and finally by participants low on agency and low on communion (all groups significantly different from each other at $p<.001)$.

${ }^{3}$ The finding that religiosity and age both explained $1 \%$ of the variance in self-esteem may seem small. Note, however, that similarly small portions of variance can be meaningful and important (Abelson, 1985). For example, the portion of variance in heart rate variability explained by the body mass index (BMI) is also only 1\% (Uusitalo, Vanninen, Levalahti, Battie, Videman, \& Kaprio, 2007). Irrespective of this, we did not set out to explain as much variance in self-esteem as possible, but instead tested a theoretical model that ascribes selfcentrality a crucial moderating role in the effect of personality on self-esteem. Given that the present (preexisting) dataset unfortunately does not include direct measures of self-centrality, we focused on four indirect indicators and found supportive evidence for our theoretical model for each indirect indicator (despite examining the indicators simultaneously). 
Figure 1. Relation between agency and self-esteem (controlling for communion) and communion and self-esteem (controlling for agency). The left panel depicts these relations for participants high on all four communion-favoring factors. The middle panel depicts these relations for all participants. The right panel depicts these relations for participants high on all four agency-favoring factors. All $p \mathrm{~s}<.001$.

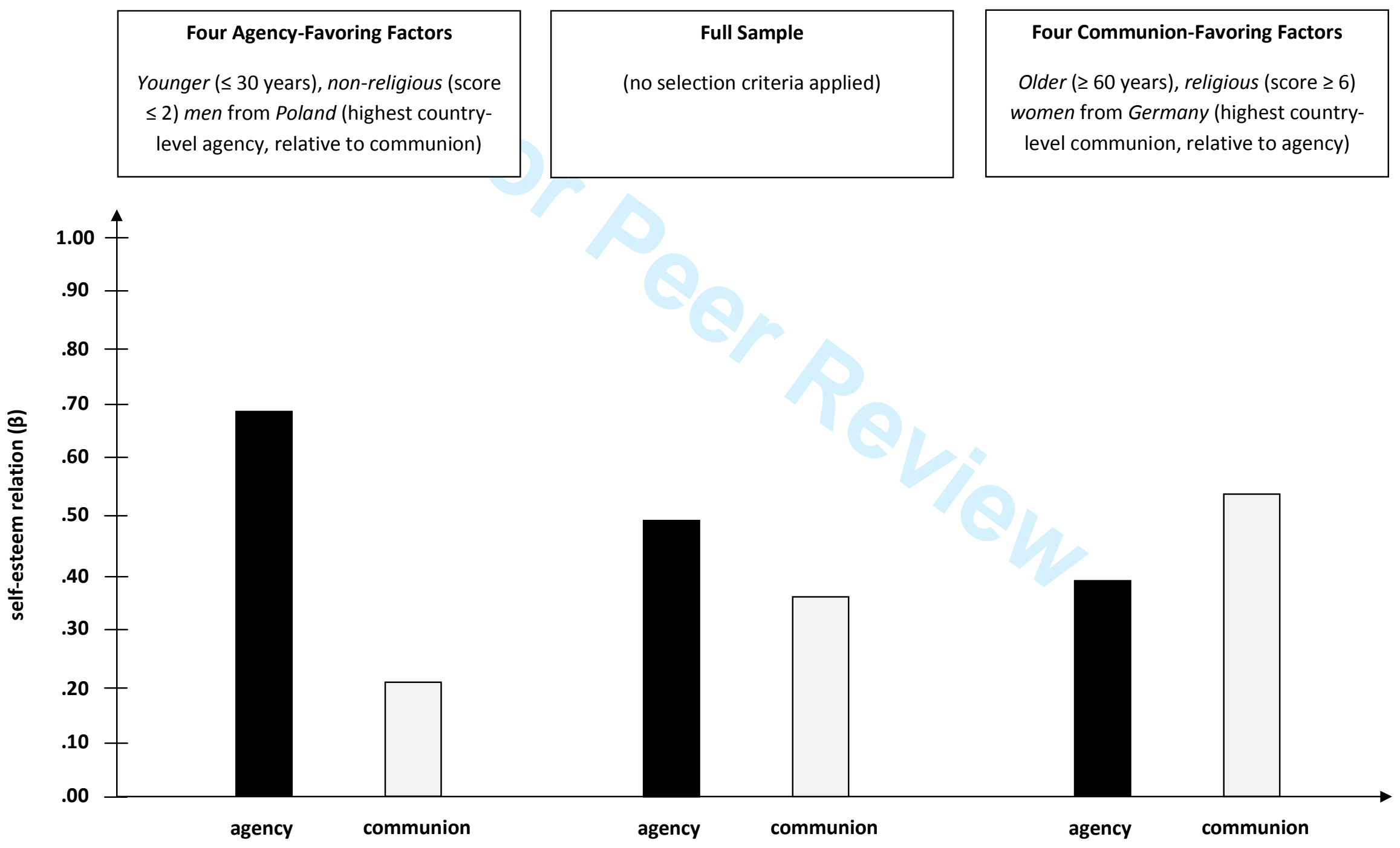


Table 1. Correlation matrix, descriptive statistics, and mean inter-item correlations of multiitem measures.

\begin{tabular}{|lccc|ccc|}
\hline \multirow{2}{*}{ self-esteem } & self-esteem & agency & communion & religiosity & sex & age \\
\hline agency & .51 & & & & & \\
communion & .61 & .45 & & & & \\
religiosity & .52 & .33 & .59 & & & \\
sex & .14 & .18 & .12 & -- & -- & \\
\hline age & -.11 & .08 & -.12 & -.05 & -- \\
M & -.09 & -.17 & .03 & -.07 & -.06 & 37.49 \\
SD & 5.05 & 4.47 & 5.76 & 3.40 & 0.53 & 12.22 \\
\hline
\end{tabular}

Note. All correlations significant at $p<.001$; mean inter-item correlations of each measure are presented in the diagonal; self-esteem correlations involve the self-esteem $g$-factor, whereas self-esteem's descriptive statistics and the mean inter-item correlation are based on the nonfactored 12-item scale; $N=187,643$. 
Table 2. Results of the two-level model.

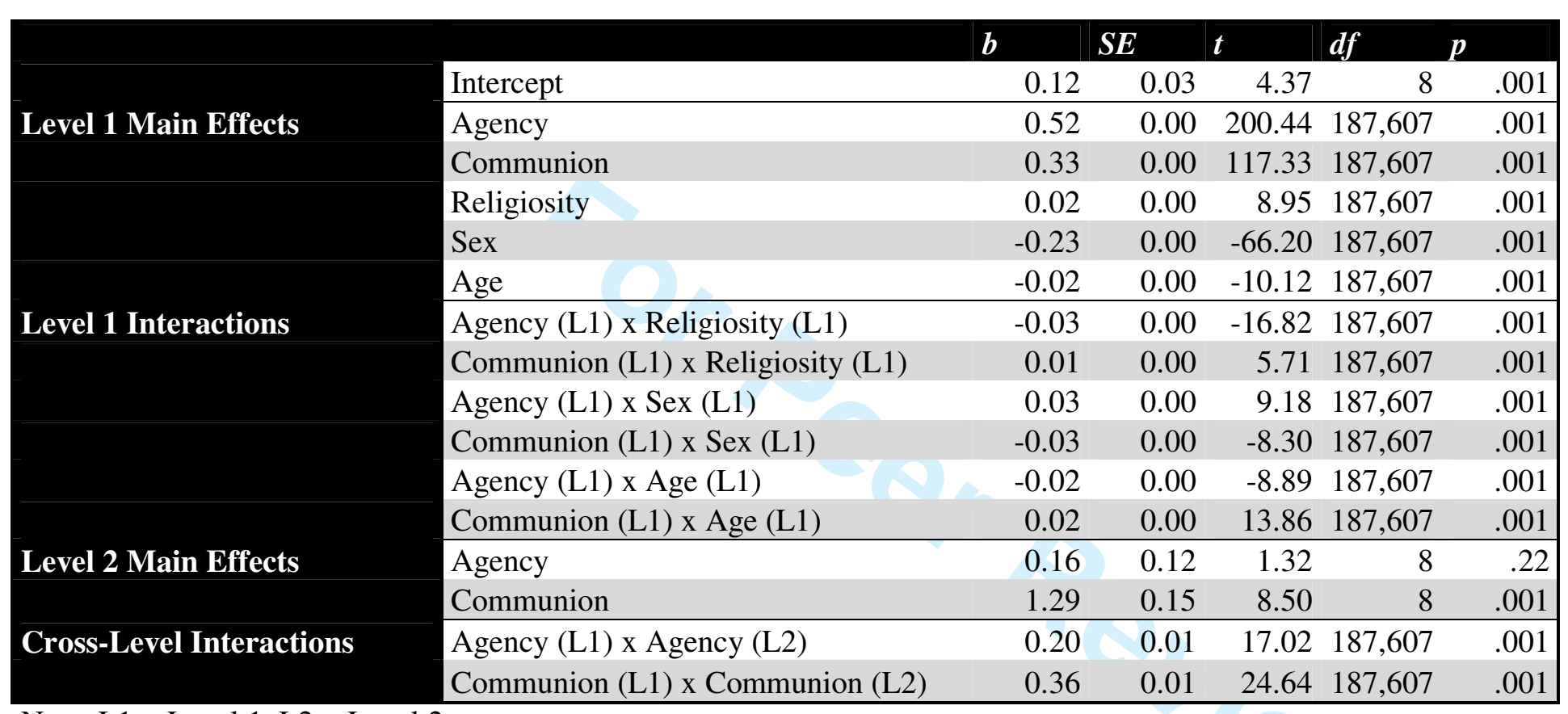

Note. L1 = Level 1, L2 = Level 2. 